\title{
Update: Interim Guidance for Health Care Providers Caring for Pregnant Women with Possible Zika Virus Exposure — United States, July 2016
}

\author{
Titilope Oduyebo, $\mathrm{MD}^{1}$; Irogue Igbinosa, $\mathrm{MD}^{2}$; Emily E. Petersen, $\mathrm{MD}^{1}$; Kara N.D. Polen, $\mathrm{MPH}^{2}$; Satish K. Pillai, MD 3 ; Elizabeth C. Ailes, PhD²; \\ Julie M. Villanueva, $\mathrm{PhD}^{3}$; Kim Newsome, $\mathrm{MPH}^{2}$; Marc Fischer, $\mathrm{MD}^{4}$; Priya M. Gupta, $\mathrm{MPH}^{5}$; Ann M. Powers, PhD ${ }^{4}$; Margaret Lampe, MPH${ }^{6}$; \\ Susan Hills, MBBS ${ }^{4}$; Kathryn E. Arnold, $\mathrm{MD}^{2}$; Laura E. Rose, $\mathrm{MTS}^{3}$; Carrie K. Shapiro-Mendoza, $\mathrm{PhD}^{1}$; Charles B. Beard, PhD ${ }^{4}$; \\ Jorge L. Muñoz, $\mathrm{PhD}^{4}$; Carol Y. Rao, $\mathrm{ScD}^{7}$; Dana Meaney-Delman, $\mathrm{MD}^{8}$; Denise J. Jamieson, $\mathrm{MD}^{1}$; Margaret A. Honein, $\mathrm{PhD}^{2}$
}

\section{On July 25, 2016, this report was posted as an MMWR Early Release on the MMWR website (http://www.cdc.gov/mmwr).}

CDC has updated its interim guidance for U.S. health care providers caring for pregnant women with possible Zika virus exposure, to include the emerging data indicating that Zika virus RNA can be detected for prolonged periods in some pregnant women. To increase the proportion of pregnant women with Zika virus infection who receive a definitive diagnosis, CDC recommends expanding real-time reverse transcription-polymerase chain reaction (rRT-PCR) testing. Possible exposures to Zika virus include travel to or residence in an area with active Zika virus transmission, or sex* with a partner who has traveled to or resides in an area with active Zika virus transmission without using condoms or other barrier methods to prevent infection. ${ }^{\dagger}$ Testing recommendations for pregnant women with possible Zika virus exposure who report clinical illness consistent with Zika virus disease ${ }^{\S}$ (symptomatic pregnant women) are the same, regardless of their level of exposure (i.e., women with ongoing risk for possible exposure, including residence in or frequent travel to an area with active Zika virus transmission, as well as women living in areas without Zika virus transmission who travel to an area with active Zika virus transmission, or have unprotected sex with a partner who traveled to or resides in an area with active Zika virus transmission). Symptomatic pregnant women who are evaluated $<2$ weeks after symptom onset should receive serum and urine Zika virus rRT-PCR testing. Symptomatic pregnant women who are evaluated 2-12 weeks after symptom onset should first receive a Zika virus immunoglobulin (IgM) antibody test; if the IgM antibody test result is positive or equivocal, serum and urine rRT-PCR testing should be performed. Testing recommendations for pregnant women with possible Zika virus exposure who do not report clinical illness consistent with Zika virus disease (asymptomatic pregnant women) differ based on the circumstances of possible

\footnotetext{
${ }^{*}$ Sex is specifically defined as vaginal sex (penis-to-vagina sex), anal sex (penisto-anus sex), oral sex (mouth-to-penis sex or mouth-to-vagina sex), and the sharing of sex toys.

$\dagger$ Barrier methods include male or female condoms for vaginal or anal sex, male condoms for oral sex (mouth-to-penis), and male condoms cut to create a flat barrier or dental dams for oral sex (mouth-to-vagina).

${ }^{\S}$ Zika virus disease is defined as having at least one of the following signs or symptoms: acute onset of fever, rash, arthralgia, conjunctivitis, and laboratory confirmation of Zika virus infection.
}

exposure. For asymptomatic pregnant women who live in areas without active Zika virus transmission and who are evaluated $<2$ weeks after last possible exposure, rRT-PCR testing should be performed. If the rRT-PCR result is negative, a Zika virus IgM antibody test should be performed 2-12 weeks after the exposure. Asymptomatic pregnant women who do not live in an area with active Zika virus transmission, who are first evaluated 2-12 weeks after their last possible exposure should first receive a Zika virus IgM antibody test; if the IgM antibody test result is positive or equivocal, serum and urine rRT-PCR should be performed. Asymptomatic pregnant women with ongoing risk for exposure to Zika virus should receive Zika virus IgM antibody testing as part of routine obstetric care during the first and second trimesters; immediate rRT-PCR testing should be performed when IgM antibody test results are positive or equivocal. This guidance also provides updated recommendations for the clinical management of pregnant women with confirmed or possible Zika virus infection. These recommendations will be updated when additional data become available.

\section{Introduction}

Zika virus continues to spread worldwide, and as of July 21, 2016, 50 countries and territories reported active Zika virus transmission (locations with mosquitoes transmitting Zika virus to persons in the area). 9 Although most persons with Zika virus infection are asymptomatic or have mild clinical disease, infection during pregnancy can cause congenital microcephaly and other brain defects (1). Zika virus has also been linked to other adverse pregnancy outcomes, including miscarriage and stillbirth $(1,2)$. The U.S. Zika Pregnancy Registry (USZPR)** and the Puerto Rico Zika Active Pregnancy Surveillance System (ZAPPS $)^{\dagger \dagger}$ were established in collaboration with state, tribal, local, and territorial health departments to monitor pregnant women with confirmed or possible Zika virus infection to determine the risk for Zika virus infection during pregnancy and the spectrum of conditions associated with congenital Zika virus infection (3). As of July 14, 2016, a total of 400 women in the 50 U.S. states and the District of Columbia, and 378 women in

\footnotetext{
Sttp://www.cdc.gov/zika/geo/active-countries.html.

** http://www.cdc.gov/zika/hc-providers/registry.html.

$t_{\dagger}$ http://www.cdc.gov/zika/public-health-partners/zapss.html.
} 
all U.S. territories (aggregated territories' data from the USZPR and ZAPSS) were determined to have laboratory evidence of confirmed or possible Zika virus infection during pregnancy. $\$ \$$

Data from the USZPR and published case reports indicate that Zika virus RNA can persist in serum of some pregnant women longer than had been previously reported; the longest documented duration of Zika virus RNA detection in serum is 10 weeks after symptom onset (4-7). In addition, recent data indicate that Zika virus RNA might be detected in the serum or urine of some asymptomatic pregnant women $(7)$. The frequency of this finding is unknown, but the detection of Zika virus RNA in serum or urine provides a definitive diagnosis of Zika virus infection. Preliminary data suggest that plaque reduction neutralization testing (PRNT) might not discriminate between Zika virus and other flavivirus infections, particularly in persons with previous flavivirus exposure (8), which complicates interpretation of serologic testing (IgM antibody test and PRNT). Given these challenges, expanded rRT-PCR testing might provide a definitive diagnosis for more pregnant women who are infected with Zika virus.

CDC has revised its interim guidance for U.S. health care providers caring for pregnant women with possible Zika virus exposure. The revised testing recommendations extend the timeframe for rRT-PCR testing of serum and include rRT-PCR testing for some asymptomatic pregnant women. CDC continues to evaluate all available evidence and will update recommendations as new information becomes available.

\section{Updated Recommendations for Evaluating and Testing of Pregnant Women with Possible Zika Virus Exposure}

All pregnant women in the United States and U.S. territories should be assessed for possible Zika virus exposure at each prenatal care visit. CDC recommends that pregnant women not travel to an area with active Zika virus transmission $(9,10)$. Pregnant women who must travel to one of these areas should strictly follow steps to prevent mosquito bites during the trip. 99 In addition, it is recommended that pregnant women with a sex partner who has traveled to or lives in an area with active Zika virus transmission use condoms or other barrier methods to prevent infection or abstain from sex for the duration of the pregnancy (11).

Symptomatic pregnant women. Pregnant women who report signs or symptoms consistent with Zika virus disease (acute onset of fever, rash, arthralgia, conjunctivitis) should be tested for Zika virus infection (Figure). The testing recommendations for symptomatic pregnant women are the same

\footnotetext{
\$\$ https://www.cdc.gov/zika/geo/pregwomen-uscases.html.

$99 \mathrm{http}: / /$ wwwnc.cdc.gov/travel/page/avoid-bug-bites.
}

regardless of the circumstances of possible exposure; however, the type of testing recommended varies depending on the time of evaluation relative to symptom onset. Testing of serum and urine by rRT-PCR is recommended for pregnant women who seek care $<2$ weeks after symptom onset. This recommendation extends the previous recommendation for testing of serum from $<1$ week after symptom onset to $<2$ weeks (Figure). A positive rRT-PCR result confirms the diagnosis of recent maternal Zika virus infection. Symptomatic pregnant women with negative rRT-PCR results should receive both Zika virus IgM and dengue virus IgM antibody testing. If Zika virus rRT-PCR testing is requested from laboratories that do not have IgM antibody testing capacity or a process to forward specimens to another testing laboratory, storing of additional serum samples is recommended for $\operatorname{IgM}$ antibody testing in the event of a negative rRT-PCR result (12). If either the Zika virus or dengue virus IgM antibody test yields positive or equivocal results, PRNT should be performed on the same IgM-tested sample or a subsequently collected sample to rule out false-positive results (8).

Symptomatic pregnant women who seek care 2-12 weeks after symptom onset should first receive Zika virus and dengue virus IgM antibody testing (Figure). If the Zika virus IgM antibody testing yields positive or equivocal results, reflex rRTPCR testing should be automatically performed on the same serum sample to determine whether Zika virus RNA is present. A positive rRT-PCR result confirms the diagnosis of recent maternal Zika virus infection. However, if the rRT-PCR result is negative, a positive or equivocal Zika virus IgM antibody test result should be followed by PRNT. Positive or equivocal dengue IgM antibody test results with a negative Zika virus IgM antibody test result should also be confirmed by PRNT. Interpretation of serologic results has been described (8).

Asymptomatic pregnant women. Testing recommendations for asymptomatic pregnant women with possible Zika virus exposure differ based on the circumstances of possible exposure (i.e., ongoing versus limited exposure) and the elapsed interval since the last possible Zika virus exposure (Figure). Asymptomatic pregnant women living in areas without active Zika virus transmission who are evaluated $<2$ weeks after possible Zika virus exposure should be offered serum and urine rRT-PCR testing (Figure). A positive rRT-PCR result confirms the diagnosis of recent maternal Zika virus infection. However, because viral RNA in serum and urine declines over time and depends on multiple factors, asymptomatic pregnant women with a negative rRT-PCR result require additional testing to exclude infection. These women should return 2-12 weeks after possible Zika virus exposure for Zika virus IgM antibody testing. A positive or equivocal IgM antibody test result should be confirmed by PRNT. 
FIGURE. Updated interim guidance: testing and interpretation recommendations ${ }^{*, t, \S, \uparrow}$ for a pregnant woman with possible exposure to Zika virus $^{* *}$ — United States (including U.S. territories)

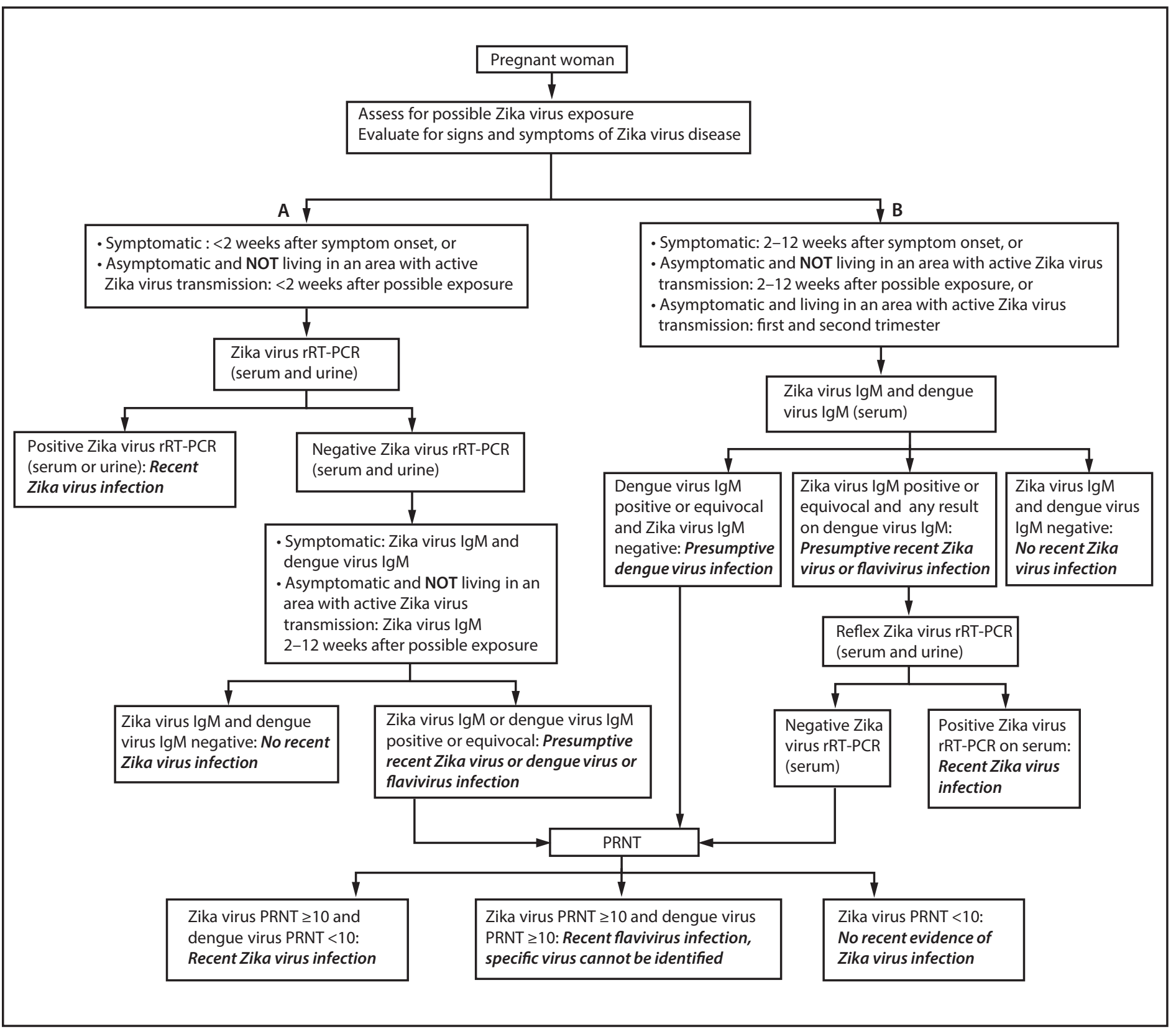

Abbreviations: IgM = immunoglobulin M; PRNT = plaque reduction neutralization test; $r R T-P C R=$ real-time reverse transcription-polymerase chain reaction.

* A pregnant woman is considered symptomatic if one or more signs or symptoms (acute onset of fever, rash, arthralgia, or conjunctivitis) consistent with Zika virus disease is reported. A pregnant woman is considered asymptomatic if these symptoms are not reported.

† Testing includes Zika virus rRT-PCR on serum and urine samples, Zika virus and dengue virus lgM, and PRNT on serum samples. PRNT results that indicate recent flavivirus infection should be interpreted in the context of the currently circulating flaviviruses. Refer to the laboratory guidance for updated testing recommendations (http://www.cdc.gov/zika/laboratories/lab-guidance.html). Because of the overlap of symptoms in areas where other viral illness are endemic, evaluate for possible dengue or chikungunya virus infection.

$\S$ Dengue virus IgM antibody testing is recommended only for symptomatic pregnant women.

II If Zika virus rRT-PCR testing is requested from laboratories without IgM antibody testing capacity or a process to forward specimens to another testing laboratory, storing of additional serum samples is recommended for IgM antibody testing in the event of an rRT-PCR negative result.

** Possible exposure to Zika virus includes travel to or residence in an area with active Zika virus transmission (http://wwwnc.cdc.gov/travel/notices/), or sex (vaginal sex (penis-to-vagina sex), anal sex (penis-to-anus sex), oral sex (mouth-to-penis sex or mouth-to-vagina sex), and the sharing of sex toys) without a barrier method to prevent infection (male or female condoms for vaginal or anal sex, male condoms for oral sex (mouth-to-penis), and male condoms cut to create a flat barrier or dental dams for oral sex (mouth-to-vagina) with a partner who traveled to, or lives in an area with active Zika virus transmission. 
Asymptomatic pregnant women living in an area without active Zika virus transmission, who seek care $2-12$ weeks after possible Zika virus exposure, should be offered Zika virus IgM antibody testing (Figure). If the Zika virus IgM antibody test yields positive or equivocal results, reflex rRT-PCR testing should be performed on the same sample. If the rRT-PCR result is negative, PRNT should be performed.

As recommended in previous guidance $(9,13)$, IgM antibody testing is recommended as part of routine obstetric care during the first and second trimesters for asymptomatic pregnant women who have an ongoing risk for Zika virus exposure (i.e., residence in or frequent travel to an area with active Zika virus transmission) (Figure). Reflex rRT-PCR testing is recommended for women who have a positive or equivocal Zika virus IgM antibody test results because rRT-PCR testing provides the potential for a definitive diagnosis of Zika virus infection. Negative rRT-PCR results after a positive or equivocal Zika virus IgM antibody test result should be followed by PRNT. The decision to implement testing of asymptomatic pregnant women with ongoing risk for Zika virus exposure should be made by local health officials based on information about levels of Zika virus transmission and laboratory capacity.

Symptomatic and asymptomatic pregnant women who seek care $>12$ weeks after symptom onset or possible Zika virus exposure. For symptomatic and asymptomatic pregnant women with possible Zika virus exposure who seek care $>12$ weeks after symptom onset or possible exposure, IgM antibody testing might be considered. If fetal abnormalities are present, rRT-PCR testing should also be performed on maternal serum and urine. However, a negative IgM antibody test or rRT-PCR result $>12$ weeks after symptom onset or possible exposure does not rule out recent Zika virus infection because IgM antibody and viral RNA levels decline over time. Given the limitations of testing beyond 12 weeks after symptom onset or possible exposure, serial fetal ultrasounds should be considered.

\section{Updated Recommendations for Prenatal Management of Pregnant Women with Laboratory Evidence of Confirmed or Possible Zika Virus Infection}

Laboratory evidence of a confirmed recent Zika virus infection includes 1) detection of Zika virus or Zika virus RNA or antigen in any body fluid or tissue specimen or 2) positive or equivocal Zika virus or dengue virus IgM antibody test results on serum or cerebrospinal fluid with a positive $(\geq 10)$ PRNT titer for Zika virus together with a negative $(<10)$ PRNT titer for dengue virus (8). However, given that serology test results can be difficult to interpret, particularly in persons who were previously infected with or vaccinated against flaviviruses, and because the adverse outcomes caused by Zika virus infection during pregnancy are not fully described, pregnant women with laboratory evidence of recent flavivirus infection are considered to have possible Zika virus infection and should be monitored frequently (Table).

Pregnant women with confirmed or possible Zika virus infection should be managed in accordance with the updated CDC Interim Guidance (Table). In addition, pregnant women with presumptive recent $Z$ ika virus or flavivirus infection (i.e., positive or equivocal Zika virus or dengue virus IgM antibody test result that needs to be confirmed by PRNT) should also be managed in accordance with this updated guidance (Table) until final results are available. Serial fetal ultrasounds (every 3-4 weeks) should be considered to assess fetal anatomy, particularly neuroanatomy, and to monitor growth. Ultrasound findings that have been associated with congenital Zika virus syndrome include microcephaly, intracranial calcifications, ventriculomegaly, arthrogryposis, and abnormalities of the corpus callosum, cerebrum, cerebellum, and eyes $(1,14)$. Consideration of amniocentesis should be individualized, because data about its usefulness in diagnosing congenital Zika virus infection are limited (13). The presence of Zika virus RNA in the amniotic fluid might indicate fetal infection $(5,15)$; however, a negative result does not exclude congenital Zika virus infection (13). In addition, persistent detection of Zika virus RNA in serum has been reported during pregnancy ( 7 ). The clinical implications of prolonged detection of Zika virus RNA in serum are not known; however, repeat rRT-PCR testing has been performed in some cases $(5,7)$.

\section{Updated Recommendations for Postnatal Management of Pregnant Women with Laboratory Evidence of Confirmed or Possible Zika Virus Infection}

Infants born to women with laboratory evidence of confirmed or possible Zika virus infection should be evaluated for congenital Zika virus infection in accordance with CDC interim guidance for health care providers caring for infants with possible Zika virus infection. (16). Zika virus testing is recommended for these infants regardless of the presence or absence of phenotypic abnormalities (14). Previous published guidance recommended that testing be performed on cord blood or infant serum; however, the use of cord blood to diagnose other congenital viral infections, such as HIV and syphilis, has sometimes yielded inaccurate results (17-20). Maternal blood can contaminate cord blood specimens leading to falsepositive results, whereas Wharton's jelly in the umbilical cord can yield false-negative results $(19,20)$. Cord blood samples 
Morbidity and Mortality Weekly Report

TABLE. Clinical management of a pregnant woman with suspected Zika virus infection

\begin{tabular}{|c|c|c|}
\hline & Prenatal management & Postnatal management \\
\hline $\begin{array}{l}\text { Recent flavivirus infection; } \\
\text { specific virus cannot be } \\
\text { identified }\end{array}$ & $\begin{array}{l}\text { Consider serial ultrasounds every } 3-4 \text { weeks to assess fetal } \\
\text { anatomy and growth. }{ }^{\dagger} \text { Decisions regarding amniocentesis } \\
\text { should be individualized for each clinical circumstance. }{ }^{\S}\end{array}$ & $\begin{array}{l}\text { Live births: Cord blood and infant serum should be tested for } \\
\text { Zika virus by rRT-PCR, and for Zika IgM and dengue virus IgM } \\
\text { antibodies. If CSF is obtained for other reasons, it can also be } \\
\text { tested. Zika virus rRT-PCR and IHC staining of umbilical cord } \\
\text { and placenta are recommended.9 Fetal losses: Zika virus } \\
\text { rRT-PCR and IHC staining of fetal tissues is recommended.9 }\end{array}$ \\
\hline $\begin{array}{l}\text { Presumptive recent flavivirus } \\
\text { infection** }^{* *}\end{array}$ & $\begin{array}{l}\text { Consider serial ultrasounds every } 3-4 \text { weeks to assess fetal } \\
\text { anatomy and growth. }{ }^{\dagger} \text { Amniocentesis might be considered; } \\
\text { decisions should be individualized for each clinical } \\
\text { circumstance. }\end{array}$ & 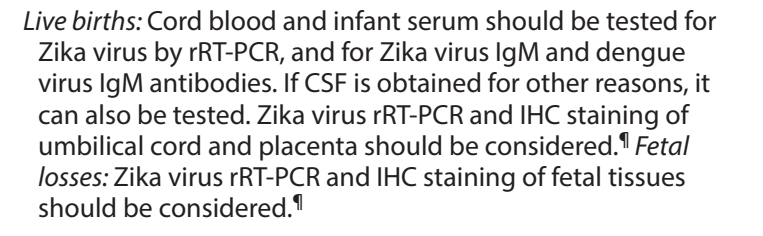 \\
\hline & \multirow{2}{*}{\multicolumn{2}{|c|}{$\begin{array}{l}\text { Clinical management in accordance with existing guidelines. }{ }^{\dagger \dagger} \\
\text { Prenatal ultrasound to evaluate for fetal abnormalities consistent with congenital Zika virus syndrome. }{ }^{\dagger} \text { Fetal abnormalities present: } \\
\text { repeat Zika virus rRT-PCR and IgM test; base clinical management on corresponding laboratory results. Fetal abnormalities absent: } \\
\text { base obstetric care on the ongoing risk for Zika virus exposure risk to the pregnant woman. }\end{array}$}} \\
\hline $\begin{array}{l}\text { No evidence of Zika virus or } \\
\text { dengue virus infection }\end{array}$ & & \\
\hline \multicolumn{3}{|c|}{ 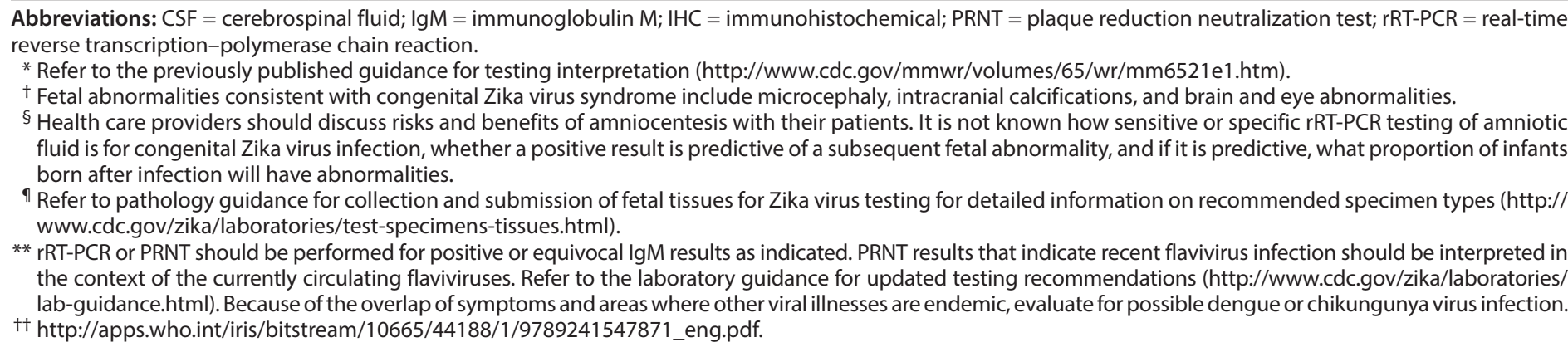 } \\
\hline
\end{tabular}

can also become clotted, which does not allow for appropriate serologic testing. Therefore, although collection and testing of cord blood for Zika virus testing can be performed, these results should be interpreted in conjunction with infant serum results. Pathology evaluation of fetal tissue specimens (e.g., placenta and umbilical cord) ${ }^{* * *}$ is another important diagnostic tool to establish the presence of maternal Zika virus infection and can provide a definitive diagnosis for pregnant women with Zika virus infection whose serology results indicate recent unspecified flavivirus infection. In addition, pathology findings might also be helpful in evaluating pregnant women who seek care $>12$ weeks after symptom onset or possible exposure; Zika virus RNA has been reported to persist in tissue specimens including placenta and fetal brain (21). A positive rRT-PCR or immunohistochemical staining on the placenta indicates the presence of maternal infection (21).

Pregnant women with laboratory evidence of confirmed or possible Zika virus infection who experience a fetal loss or stillbirth should be offered pathology testing for Zika virus infection; testing includes rRT-PCR and immunohistochemical staining of fixed tissue (21). This testing might provide insight into the etiology of the fetal loss, which could inform a woman's future pregnancy planning. Additional information is available at http://www.cdc.gov/zika.

\section{Acknowledgments}

Aron J. Hall, Division of Viral Diseases, National Center for Immunization and Respiratory Diseases, CDC; Amy J. Lambert, Ronald M. Rosenberg, Division of Vector-Borne Diseases, National Center for Emerging and Zoonotic Infectious Diseases, CDC; Diane Morof, Division of Reproductive Health, National Center for Chronic Disease Prevention and Health Promotion, CDC; Evelyn M. Rodriguez, Division of Global HIV/AIDS and Tuberculosis, Center for Global Health, CDC; Gail Thompson, Toby L. Merlin, Division of Preparedness and Emerging Infections, National Center for Emerging and Zoonotic Infectious Diseases, CDC; Heather J. Menzies, Division Of Global Health Protection, Center for Global Health, CDC; John R. Sims, Division of Congenital and Developmental Disorders, National Center on Birth Defects and Developmental Disabilities, CDC; Angela D. Aina, Karen R. Broder, Division Of Healthcare Quality Promotion, National Center for Emerging and Zoonotic Infectious Diseases, CDC; Rita M. Traxler, Division Of High-Consequence Pathogens and Pathology, National Center for Emerging and Zoonotic Infectious Diseases, CDC.

\footnotetext{
*** http://www.cdc.gov/zika/laboratories/test-specimens-tissues.html.
} 
${ }^{1}$ Division of Reproductive Health, National Center for Chronic Disease Prevention and Health Promotion, CDC; ${ }^{2}$ Division of Congenital and Developmental Disorders, National Center on Birth Defects and Developmental Disabilities, CDC; ${ }^{3}$ Division of Preparedness and Emerging Infections, National Center for Emerging and Zoonotic Infectious Diseases, CDC; ${ }^{4}$ Division of Vector-Borne Diseases, National Center for Emerging and Zoonotic Infectious Diseases, CDC; 5 Division of Nutrition, Physical Activity, and Obesity, National Center for Chronic Disease Prevention and Health Promotion, CDC; ${ }^{6}$ Division of HIV/AIDS Prevention, National Center for HIV/AIDS, Viral Hepatitis, STD, and TB Prevention, CDC; ${ }^{7}$ Division Of Global Health Protection, Center for Global Health, CDC; ${ }^{8}$ Office of the Director, National Center for Emerging and Zoonotic Infectious Diseases, CDC.

Corresponding author: Titilope Oduyebo, 770-488-7100, ZikaMCH@cdc.gov.

\section{References}

1. Rasmussen SA, Jamieson DJ, Honein MA, Petersen LR. Zika virus and birth defects - reviewing the evidence for causality. N Engl J Med 2016;374:1981-7. http://dx.doi.org/10.1056/NEJMsr1604338

2. Meaney-Delman D, Rasmussen SA, Staples JE, et al. Zika virus and pregnancy: what obstetric health care providers need to know. Obstet Gynecol 2016;127:642-8. http://dx.doi.org/10.1097/AOG.0000000000001378

3. Simeone RM, Shapiro-Mendoza CK, Meaney-Delman D, et al.; Zika and Pregnancy Working Group. Possible Zika virus infection among pregnant women-United States and Territories, May 2016. MMWR Morb Mortal Wkly Rep 2016;65:514-9. http://dx.doi.org/10.15585/mmwr.mm6520e1

4. Bocanegra C, Sulleiro E, Soriano-Arandes A, et al. Zika virus infection in pregnant women in Barcelona, Spain. Clin Microbiol Infect. In press 2016.

5. Driggers RW, Ho CY, Korhonen EM, et al. Zika virus infection with prolonged maternal viremia and fetal brain abnormalities. N Engl J Med 2016;374:2142-51. http://dx.doi.org/10.1056/NEJMoa1601824

6. Pacheco O, Beltrán M, Nelson CA, et al. Zika virus disease in Colombiapreliminary report. N Engl J Med 2016;NEJMoa1604037. http://dx.doi. org/10.1056/NEJMoa1604037

7. Meaney-Delman D, Oduyebo T, Polen KND, et al. Prolonged detection of Zika virus RNA in pregnant women. Obstet Gynecol In press 2016.

8. Rabe IB, Staples JE, Villanueva J, et al. Interim guidance for interpretation of Zika virus antibody test results. MMWR Morb Mortal Wkly Rep 2016;65:543-6. http://dx.doi.org/10.15585/mmwr.mm6521e1

9. Oduyebo T, Petersen EE, Rasmussen SA, et al. Update: interim guidelines for health care providers caring for pregnant women and women of reproductive age with possible Zika virus exposure-United States, 2016. MMWR Morb Mortal Wkly Rep 2016;65:122-7. http://dx.doi. org/10.15585/mmwr.mm6505e2
10. Petersen EE, Staples JE, Meaney-Delman D, et al. Interim guidelines for pregnant women during a Zika virus outbreak-United States, 2016. MMWR Morb Mortal Wkly Rep 2016;65:30-3. http://dx.doi.org/10.15585/mmwr.mm6502e1

11. Oster AM, Russell K, Stryker JE, et al. Update: interim guidance for prevention of sexual transmission of Zika virus-United States, 2016. MMWR Morb Mortal Wkly Rep 2016;65:323-5. http://dx.doi. org/10.15585/mmwr.mm6512e3

12. CDC. CDC Recommendations for subsequent Zika IgM antibody testing. Atlanta, GA: US Department of Health and Human Services, CDC; 2016. http://emergency.cdc.gov/han/han00392.asp

13. Petersen EE, Polen KN, Meaney-Delman D, et al. Update: interim guidance for health care providers caring for women of reproductive age with possible Zika virus exposure-United States, 2016. MMWR Morb Mortal Wkly Rep 2016;65:315-22. http://dx.doi.org/10.15585/mmwr.mm6512e2

14. Franca GV, Schuler-Faccini L, Oliveira WK, et al. Congenital Zika virus syndrome in Brazil: a case series of the first 1501 livebirths with complete investigation. Lancet 2016. Epub June 29, 2016. http://www.thelancet. $\mathrm{com} / \mathrm{pdfs} /$ journals/lancet/PIIS0140-6736(16)30902-3.pdf

15. Meaney-Delman D, Hills SL, Williams C, et al. Zika Virus infection among U.S. pregnant travelers-August 2015-February 2016. MMWR Morb Mortal Wkly Rep 2016;65:211-4. http://dx.doi.org/10.15585/mmwr.mm6508e1

16. Fleming-Dutra KE, Nelson JM, Fischer M, et al. Update: interim guidelines for health care providers caring for infants and children with possible Zika virus infection-United States, February 2016. MMWR Morb Mortal Wkly Rep 2016;65:182-7. http://dx.doi.org/10.15585/mmwr.mm6507e1

17. Lo YM, Lo ES, Watson N, et al. Two-way cell traffic between mother and fetus: biologic and clinical implications. Blood 1996;88:4390-5.

18. Masuzaki H, Miura K, Miura S, et al. Labor increases maternal DNA contamination in cord blood. Clin Chem 2004;50:1709-11. http:// dx.doi.org/10.1373/clinchem.2004.036517

19. Chhabra RS, Brion LP, Castro M, Freundlich L, Glaser JH. Comparison of maternal sera, cord blood, and neonatal sera for detecting presumptive congenital syphilis: relationship with maternal treatment. Pediatrics 1993;91:88-91.

20. Workowski KA, Bolan GA. Sexually transmitted diseases treatment guidelines, 2015. MMWR Recomm Rep 2015;64(RR-03).

21. Martines RB, Bhatnagar J, de Oliveira Ramos AM, et al. Pathology of congenital Zika syndrome in Brazil: a case series. Lancet 2016. Epub June 29, 2016. http:// thelancet.com/pdfs/journals/lancet/PIS0140-6736(16)30883-2.pdf 